\title{
Smart Garments - the Issue of Usability and Aesthetics
}

\author{
Andreas Sonderegger \\ Department of psychology \\ University of Fribourg \\ Rue Faucigny 2 \\ $\mathrm{CH}-1700$ Fribourg \\ andreas.sonderegger@unifr.ch
}

\begin{abstract}
In this position paper, important issues to consider for the development of smart garments are addressed. A special emphasis is placed on usability and its evaluation in a user-centered design approach. Different factors influencing the outcomes of usability tests are discussed. The effect of design aesthetics as a very important influencing factor in usability tests is addressed in detail and its potential influence on the outcomes of usability evaluations of smart garments is discussed. The paper concludes with recommendations for the development of usable and enjoyable smart garments.
\end{abstract}

\section{Keywords}

Smart clothes; usability test; user experience; design aesthetics; wearable computers; longitudinal usability evaluation

\section{Introduction}

In modern societies, clothes fulfill different functions for humans wearing them. In general, it can be distinguished between two main functions: the physical and a socio-cultural function. The physical function includes e.g. the protection from elements (cold, heat, rain, UV etc.), safety during hazardous activities, protection from rough surfaces, insect bites or splinters or a hygienic barrier between the body and the environment $[31,7]$. Social and cultural functions comprise the intention of the wearer to provide the social environment with information about e.g. his or her individual, sexual, cultural or religious characteristics and social status $[7,13]$. Coming along with an increased technological progress (e.g. miniaturization of computing technology, development of new innovative fabric) however, the functionality of clothes is about to broaden significantly. It is possible nowadays to integrate technology directly into the clothes - garments are becoming 'smart'. Smart garments are clothes containing technology such as sensors, processors, communication equipment, displays or input devices that are integrated into a textile-based garment structure and provide some additional functionality compared to the classical physical and socio-cultural functions of clothing $[5,18]$. The notion of smart garments can be differentiated from other concepts stemming from the domain of wearable technology such as 'wearable computers' or 'functional clothing'. It is not the scope of this article to differentiate between these concepts (c.f. [5] for an integration of the different concepts of wearable computing in the domain of ubiquitous or pervasive computing). They all contain however three common main characteristics that can be summarized as follows: they dispose of sensors or an input device, they are 'intelligent' (i.e. they contain some sort of computing technology), they produce an output and hence provide specific functionalities that go beyond the classical main functions of clothing. Although important progress has been made with regard to the development of intelligent clothes, the number of successful smart garments on the market is still 
rather limited. This might be due to the fact that the integration of electronics and computing technology into clothing represents a difficult and challenging task for designers and system developers especially with regard to aspects of the smart garment's usability.

As for all interactive products and systems, usability and its evaluation is a key concept for the development of smart garments. In this position paper, we address specific needs when evaluating smart garments. This is done by introducing a framework which is addressing specific influencing factors in usability tests. Furthermore, the important influence of design aesthetics on the outcomes of product evaluation will be discussed in detail.

\section{Usability evaluation of smart garments}

Usability is a very important notion in the domain of product design since it is a particular challenge for product developers to design products that are easy and comfortable to use. This is also the case with regard to the development of smart garments. To ensure the development of user-friendly products, it is important to guarantee that the needs and limitations of the user are taken into account throughout the whole development process [22]. This "user-centred" approach is widely accepted in product design and embodies three main principles of design: a) early focus on users and tasks, b) empirical measurement, and c) iterative design [8]. This implies that designers should bear the end user in mind throughout the whole design process. An important and widely applied method to integrate the end user into the development process is to conduct usability tests, in which test users interact with prototypes of the product in a typical usage scenario to carry out real tasks while their performance and reactions to the product is observed, recorded, and empirically analysed $[17,8]$. The user-centred approach transferred to the design process of smart garments implies that designers should evaluate the usability of the product throughout the whole development process by means of empirical usability testing.

Usability can be defined according to the International Standards Organization (ISO) [14] as the "extent to which a product can be used by specified users to achieve specified goals with effectiveness, efficiency and satisfaction in a specified context of use" (p. 2). Effectiveness denotes the accuracy and completeness with which the user can achieve his or her goals when using the product, whereas efficiency represents the amount of resources expended in relation to the accuracy and completeness with which users achieve their goals. Satisfaction characterises the freedom from discomfort and positive attitudes towards the use of the product [14]. While effectiveness, efficiency and satisfaction are common measures in usability tests, a recent trend in usability research emphasises a more holistic approach that focuses on the physical, sensual, cognitive, aesthetic and emotional experience of product use $[15,12]$. The concept of user experience enlarges the classical notion of usability and addresses also aspects such as the user's fun, affect and emotions evoked by the human-product interaction $[10,11]$. Since the functions of clothing extend the pure functional aspect of an interactive product by physical and socio-cultural functions such as self-representation or status $[7,9]$, it may be useful for the evaluation of smart garments to capture a broad range of measures of the userproduct interaction. It is hence advisable to include, in addition to the classical usability measures (i.e. performance, satisfaction, errors etc.), the recording of experiential indicators of emotion and fun when evaluating smart garments in usability tests.

Regardless of the specific measures that are recorded in usability tests, recent research in the domain of consumer ergonomics has indicated that findings of usability tests might be biased due to the rather artificial test scenario in which usability tests usually take place. For example, it has been described as a common phenomenon that test participants in usability tests are struggling with difficulties through several tasks just to report afterwards that the product was fun and easy to use [3]. According to Dicks [3], this might be due to the unfamiliar environment in usability tests in which participants make (not accurate) assumptions about goals and scopes of the evaluation as well as about the expectations of the evaluator. Such particular results might however also be due to other contextual aspects of usability tests that influence the results of usability evaluation. 


\section{Influencing factors in usability tests - the four factor framework of contextual fidelity}

A usability test is a simulation of a real usage situation. Therefore usability practitioners cannot rely on the assumption that the modelled scenario exactly represents the real usage scenario. It depends however on the accuracy of the modelled scenario whether the usability of the product is evaluated accurately in the usability test. If the simulation does not represent the real usage scenario accurately, the measures cannot be considered as containing sufficient external validity and hence do not allow generalisation of the findings to the population or the situation of interest [30]. Usability practitioners however most often have to accept some simplifications and abstractions when designing usability tests due to reasons of measurability and efficiency. For a precise recording of user performance e.g., data collection in the real usage environment may be difficult. Therefore, usability tests are often conducted in usability laboratories, where the human-product interaction can be observed and recorded in a more detailed and accurate way (for an overview of the lab vs. field discussion see [23]). Because real usage scenarios often cannot be simulated with $100 \%$ accuracy in usability tests, it is very important for usability practitioners to be aware of the consequences of such simplifications and abstractions of usability test scenarios. This is because the lack of knowledge about the limitations of usability evaluation methods represents an important risk for undermining and trivializing the whole method of usability testing [3]. Therefore, a detailed knowledge about influencing factors in usability test scenarios is of great importance.

The Four Factor Framework of Contextual Fidelity (see figure 1 [25]) identifies the most important aspects of the testing context that may unduly influence the test outcomes. It is based on the human-machine system framework (for an overview see $[2,6])$, according to which user-product interaction consists of four principal components: user, task, tool and environment. Those four components are hence important aspects characterizing a usability test scenario. The Four Factor Framework of Contextual Fidelity picks up on these main components and describes four factors on which the testing scenario in usability tests may differ from the real usage scenario and therefore be of high (small differences) or low fidelity (severe differences). Those four factors are: system prototype, testing environment, user characteristics and task scenarios. Prototypes are often used in usability tests in place of an operational product because usability tests are for the most part conducted early in the development process when a fully operational product is not yet available. Prototypes however might differ considerably from the final product (e.g. with regard to aesthetic design, level of functionality, way of interaction etc.). This can have an influence on the results of usability tests. The second factor on which the usability test scenario can differ from the real usage scenario is the testing environment. For reasons of measurability and controllability of influencing factors, usability tests are often conducted in laboratories [22]. The lab situation however is an environment that differs considerably compared to the real usage scenario, which can have an influence on the results of usability tests. A third factor potentially influencing the outcomes of usability tests are user characteristics.

Characteristics of test participants (such as i.e. competence, attitude or state) may differ from the future user population, which might influence on the results of usability tests. As a fourth factor described by the framework, the task scenarios given in usability tests may not be representative or complex enough compared to the real usage situation. As a consequence of a restricted time budget in usability tests for example, often only a selection of possible tasks are selected. Usability practitioners assume that if users can successfully complete the selected tasks, they should also be able to complete all other tasks [3]. This assumption however might not prove true, and therefore, the choice of tasks scenarios can have an influence on the outcomes of usability tests. 


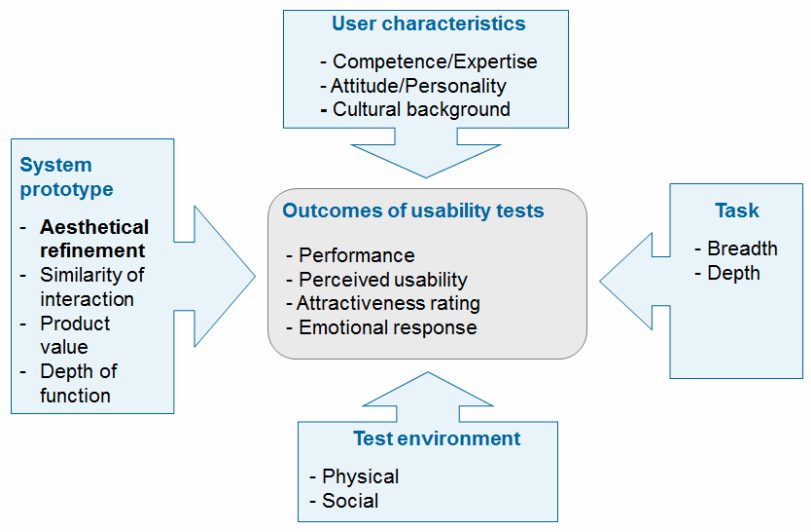

Figure 1. Four-factor framework of contextual fidelity [25, p. 132].

The four-factor framework of contextual fidelity addresses issues that need to be taken into account during the planning and completion of usability tests. This is because research in the domain of consumer ergonomics has pointed out effects of various influencing factors on usability test outcomes so far. Cultural background of test participants e.g. has been shown to influence the outcomes of usability tests of a consumer product with a high or low product value [27]. It has also been shown that the results of usability tests may depend on the setup of the usability laboratory (e.g. the presence of observers may have a negative influence on participants mood and performance) [26]. Furthermore, the use of high or low-fidelity prototypes may impinge on outcomes of usability tests [24]. While all those factors need beyond doubt to be considered when evaluating the usability of smart garments, one aspect deserves a specifically thorough consideration: the aesthetical design of the system prototype.

\section{Aesthetics and the usability evaluation of smart garments}

Since one important function of clothes is the communication of the wearer's personality and his or her relation to the social environment [9], aesthetics should play an important role in the design of smart clothes. Smart garments need to be usable but also nice to look at. With regard to the usability evaluation of smart clothes, the importance of the aesthetical function for clothes might represent a particular challenge. This is because in the past 15 years, a rather important number of research studies in consumer ergonomics have shown quite consistently that subjective usability ratings are highly correlated with ratings of the attractiveness of the product, indicating that more attractive products are also considered to be more usable (e.g. $[1,29]$ ). The relationship between design aesthetics and subjective usability ratings has been shown for a broad range of products (e.g. webpages, computer-simulated cash machines, MP3-players, mobile phones, computer software etc.) and for various different cultural backgrounds of user groups (e.g. Germany, Switzerland, Israel, Japan). Furthermore, some studies also indicated that design aesthetics influence other outcome measures of usability tests such as user behavior and user emotions (c.f. $[29,28]$ ). Such findings indicate that in a usability test it is highly probable that the different outcome measures are severely biased by the aesthetical refinement of the product prototype.

Various explanations have been put forward to address the link between aesthetics and subjective usability ratings, such as the common method bias [20] or the processing fluency theory [21]. The explanation that has been referred to most often when discussing the correlation between aesthetics and usability however is the halo effect. Also named the "what is beautiful is good"-stereotype, the halo effect has been first described in social psychology, explaining the phenomenon that physically attractive persons are considered to possess more positive personality traits compared to unattractive persons [4]. This is because more salient characteristics of a person (e.g. attractiveness) influence the perception of other, less salient characteristics (e.g. personality). With regard to usability tests, design aesthetics of a product or prototype represents an obvious and highly accessible product characteristic that can be very rapidly discerned during user-product interaction (i.e. in about $50 \mathrm{~ms}$ according to [19]). Compared to design aesthetics, aspects of system usability are less salient and require a more profound interaction with the product to be adequately identified by the user.

Although design aesthetics seems to play a very important role in usability tests, a recent study [28] has indicated that the positive influence of design aesthetics on subjective usability measures (as well as user emotions) vanes with an increased duration of the user-product interaction. After a period of 
two weeks, design aesthetics did not show any influence on usability ratings any more. This indicates that test users seem to need a rather long interaction period to be able to evaluate the usability of a product or system and that the usual two-hour lab-evaluation which is currently standard in usability practice may not be adequate. In such a short period of time, the user seems not to be capable yet to draw a true picture of a product's usability but refers for his or her evaluation basically on aesthetical design characteristics of the artifact. With regard to the usability evaluation of smart garments, it might be therefore advisable to schedule long-term user trials of several hours or even several days, especially because aesthetics play such an important role in the domain of clothing and fashion.

\section{Discussion and conclusion}

Smart clothes must meet a broad range of requirements to be accepted by the user and hence to have success on the market. As for conventional clothes, smart clothes must provide thermic and mechanic protection of the user. Furthermore, they must satisfy specific user needs with regard to fashion, self-representation and style. Finally, they need to satisfy users' needs with regard to usability and functionality. To do justice to all those requirements, it is crucial to consider the user with his or her needs and limitations throughout the whole development process, ideally by adopting a user-centered design approach. As the method of usability tests is considered to be the gold standard [16] in the user-centered design approach, smart garments should ideally be evaluated throughout the whole development process by means of empirical usability testing. In doing so, various influencing factors need to be considered. To prevent from a harmful influence of contextual factors in usability tests, it is advisable to create usage scenarios that are as close to the real usage situation as possible. One of the most important factors impinging on outcomes of smart garments' usability evaluations however might be the aesthetical refinement of the product or prototype used in the evaluation. Extended periods of userproduct interaction may therefore be the adequate measure to cope with the undesirable halo effect of aesthetical appeal on other outcome measure of usability tests.

\section{Acknowledgements}

This work was supported by the Swiss National Science Foundation (grant No. 100014/140359).

\section{References}

[1] Ben-Bassat, T., Meyer, J., Tractinsky, N. Economic and subjective measures of the perceived value of aesthetics and usability. ACM Transactions on Computer-Human Interaction (TOCHI), 13 (2006), 210-234.

[2] Bennett, J.L. The user interface in interactive systems. Annual Review of Information Science and Technology, 7 (1972), 159-196.

[3] Dicks, R. S. Mis-usability: on the uses and misuses of usability testing. In Proc. of the 20th annual international conference on Computer documentation, ACM Press (2002), 26-30.

[4] Dion, K., Berscheid, E., Walster, E. What is beautiful is good. Journal of personality and social psychology, 24(3) (1972), 285-290.

[5] Dunne, L.E., Ashdown, S.P. and Smyth, B. Expanding garment functionality through embedded electronic technology. Journal of Textile and Apparel, Technology and Management, 4(3) (1995), 1-11.

[6] Eason, K.D. A task-tool analysis of the manager-computer interaction. In: B. Shackel (Ed.), Man-Computer Interaction. Amsterdam: Sijthoff and Noordhoff, 1981.

[7] Flügel, J.C. The Psychology of Clothes, International Psycho-analytical Library, No.18, New York: AMS Press, 1976.

[8] Gould, J. D., Lewis, C. H. Designing for usability: Key principles and what designers think. Communications of the ACM 28, 3 (1985), 300-311.

[9] Harms, E. The Psychology of Clothes. American Journal of Sociology , 44(2) (1938), 239-250.

[10] Hartmann, J., De Angeli, A., Sutcliffe, A. Framing the User Experience: Information Biases on Website Quality Judgement. In proc. of the SIGCHI Conference on Human Factors in Computing Systems, ACM Press (2008), 855-864.

[11] Hassenzahl, M., Tractinsky, N. User experience - a research agenda. Behaviour and Information Technology, 25 (2) (2006), 91-97.

[12] Hekkert, P. Design aesthetics: principles of pleasure in design. Psychology Science, 48(2) (2006), $157-172$.

[13] Holman, R.H. Clothing as communication: an empirical investigation. Advances in Consumer Research, 7 (1980), 372-377.

[14] ISO 9241-11. Ergonomic requirements for office work with visual display terminals (VDTs)-Part 11, Guidance on usability, ISO, 1998. 
[15] Jordan, P.W. Human factors for pleasure in product use. Applied Ergonomics, 29(1) (1998), 2533.

[16] Landauer, T.K. The trouble with computers: Usefulness, Usability and productivity. Cambridge: MIT Press.

[17] Lewis, J.R. Usability testing. In: Salvendy, G. (Ed.), Handbook of Human Factors and Ergonomics (pp. 1275-1316). John Wiley, New York, 2006.

[18] Limberis, A., Paradiso, R. Smart fabrics and interactive textile enabling wearable personal applications: R\&D state of the art and future challenges. In Proc. 30th Ann. Int. IEEE EMBS Conf., (2008), 5270-5273.

[19] Lindgaard, G., Fernandes, G., Dudek, C., Brown, J. Attention web designers: you have 50 milliseconds to make a good first impression! Behaviour \& Information Technology, 25 (2006), 115-126.

[20] Podsakoff, P. M., MacKenzie, S. B., Lee, J. Y., Podsakoff, N. P. Common method biases in behavioral research: a critical review of the literature and recommended remedies. Journal of Applied Psychology, 88(5) (2003), 879-903.

[21] Reber, R., Schwarz, N., Winkielman, P. Processing fluency and aesthetic pleasure: is beauty in the perceiver's processing experience? Personality and Social Psychology Review, 8(4) (2004), 364-382.

[22] Rubin, J., Chisnell, D. Handbook of usability testing ( $2^{\text {nd }}$ ed.). Wiley, Indianapolis, 2008.

[23] Sauer, J., Sonderegger, A. Methodological issues in product evaluation: the influence of testing environment and task scenario. Applied Ergonomics, 42 (2011), 487-494.
[24] Sauer, J., Sonderegger, A. The influence of prototype fidelity and aesthetics of design in usability tests: effects on user behaviour, subjective evaluation and emotion. Applied Ergonomics, 40 (2009), 670-677.

[25] Sauer, J., Seibel, K., Rüttinger, B. The influence of user expertise and prototype fidelity in usability tests. Applied Ergonomics, 41 (2010), 130-140.

[26] Sonderegger, A., Sauer, J. The influence of laboratory set-up in usability tests: effects on user performance, subjective ratings and physiological measures. Ergonomics, 52 (11) (2009), 1350 1361.

[27] Sonderegger, A., Sauer, J. The influence of socio-cultural background and product value in usability testing. Applied Ergonomics, 44 (2013), 341-349.

[28] Sonderegger, A., Zbinden, G., Uebelbacher, A., Sauer $J$. The influence of product aesthetics and usability over the course of time: a longitudinal field experiment. Ergonomics, 55(7) (2012), 713-730.

[29] Sonderegger, A., Sauer, J. The influence of design aesthetics in usability testing: effects on user performance and perceived usability. Applied Ergonomics, 41 (2010), 403-410.

[30] Thomas, J. C., Kellogg, W. A. Minimizing ecological gaps in interface design. IEEE SOFTWARE, (1989), 78-86.

[31] Watkins, S.M. Clothing: The portable environment. Ames: Iowa State University Press, 1995. 